\section{LASERS}

\section{Isotope Separation}

from our Molecular Physics Correspondent

THE announcement of a successful separation of hydrogen isotopes by selective laser-induced chemical reaction (S. W. Mayer, M. A. Kwock, R. W. F. Gross and D. J. Spencer, Appl. Phys. Lett., 17, $516 ; 1970$ ) will carry a stage further the reputation of the laser as a magic wand which can be pointed with startling results at practically all things physicochemical.

This new application, which follows close on the development of a continuouswave hydrogen-fluorine laser in the same Aerospace Corporation group (see Appl. Phys. Lett., 16, 386; 1970), underlines more than any other so far the now complete involvement of physics with chemistry in the field of continuous-wave gas lasers. The isotope separation is achieved by irradiation of mixtures of ordinary and deuteromethanol and bromine with $0.44 \mathrm{eV}(2.64 \mu \mathrm{m})$ photons at a total power of about 100 watts $\left(6 \times 10^{20}\right.$ photons per second). Of this some 50 per cent is absorbed in the band characteristic of - $\mathrm{OH}$ groups whereas almost none is absorbed by the deutero-alcohol. Because the activation energy for attack of $\mathrm{CH}_{3} \mathrm{OH}$ by $\mathrm{Br}_{2}$ is only some $0.27 \mathrm{eV}$ $\left(25 \mathrm{~kJ} \mathrm{~mol}^{-1}\right)$ the reaction of this can be made virtually specific at laboratory temperature. Mayer and his colleagues do not actually separate the deuterated fraction but their absorption spectra show beyond doubt that the composition of the gas remaining indicates an enrichment from 50 per cent to more than 95 per cent $\mathrm{CD}_{3} \mathrm{CD}$.

It is important to notice that the selectivity exploited in this experiment depends only on the careful matching of the laser frequency to the vibration of the $-\mathrm{OH}$ bond and involves no kind of kinetic isotope effect. At the same time, because the energy of the photon is deliberately kept low, there is no actual photolysis of the alcohol and no dissociation of the bromine leading to the photobromination reactions familiar at shorter wavelengths. In fact, the process occurring is not easily labelled by any of the terms currently in use in photochemical kinetics-a sure indication of its originality and potential application. The authors, whose outlook, one imagines, is not primarily chemical, choose the rather misleading term "photocatalysis" -a better description might be simply "specific photo-activation", in line with thermal, chemical, electron impact activation and the like.

Unfortunately it does not seem likely that such a clean separation will be possible with heavier isotopes, though, given chemical ingenuity and some form of recycling arrangement, the method could be competitive with others currently available.
Whether or not this is so and whatever name comes to be given to the experiment, it will almost certainly become a classic of chemical kinetics in its own right for, forgetting about isotopes altogether, the prospect of pumping infrared energy at such power into a specific vibrational mode of a reactive molecule opens the way to the kind of observation of which experimental kineticists dream. I feel sure that we shall begin to see the fruits of this from a number of different laboratories before long.

\section{FIBRES \\ Reinforcing Boron}

from our Materials Science Correspondent

A STUDY has been made recently (J. O. Carlsson and T. Lundström, J. LessCommon Metals, 22, 317; 1971) of the efficacy of a group of solutes consisting of all $3 \mathrm{~d}$ transition metals and copper, on the indentation hardness of $\beta$-boron. All the solute metals- $\mathrm{Sc}, \mathrm{Ti}, \mathrm{V}, \mathrm{Cr}$, $\mathrm{Mn}, \mathrm{Fe}, \mathrm{Co}, \mathrm{Ni}$ and $\mathrm{Cu}-$ were arc-melted with boron at a concentration of 5 atm per cent, which in each instance was sufficient to produce a saturated solid solution (though the saturation concentration was not determined). The unit cell volumes of the solid solutions were determined and plotted against microhardness; the two variables were found to be closely correlated. The maximum increase in hardness of about 20 per cent relative to pure $\beta$-boron was obtained for $\mathrm{Cu}, \mathrm{Sc}$ and $\mathrm{Mn}$ solutes, corresponding to 1-2 per cent increase in unit cell volume.

In view of the importance of boron as a fibre-reinforcing metal, and because single crystals of boron are readily grown when transition metals are dissolved in it, Carlsson and Lundström suggest that alloyed boron should be investigated with a view to obtaining fibres or perhaps whiskers of enhanced strength.

It was recently reported from the National Physical Laboratory (S. Allen et al., Nature, 224, 684; 1969) that carbon fibre can be strengthened by alloying it with a little boron. The findings now reported for boron containing metal solutes suggest that boron fibres alloyed with carbon (assuming that any solubility exists) may turn out to be particularly strong.

\section{NIAGARA \\ Regressing Falls}

from our Geomagnetism Correspondent

THE Niagara River, like a good woman, is unusually constant. For one thing, no great uncontrolled river joins it above the principal (Horseshoe) falls; and in the drainage basin there is not much variation in discharge because upstream

\title{
Structural Inorganic Chemistry
}

ORGANOTRANSITION metal chemistry has been a definite growth point in chemistry during the past decade. The related themes of the reactivity of ligands coordinated to metals and the stabilization of unusual and reactive organic moieties through coordination are of particular importance because of their implications for mechanisms of homogeneous and heterogeneous catalysis. Diffraction methods in parallel with synthetic and mechanistic studies have provided precise data on the geometries of coordinated unsaturated ligands and the past three years have seen several attempts to evolve a generalized bonding theory. The molecules of real chemical interest are too large for any non-empirical quantum mechanical calculation of their energy levels and structure to be attempted, so much reliance has to be placed on symmetry arguments; fairly comprehensive calculations are at present restricted to such molecules as tetracarbonyl nickel. There are obvious shortcomings in this type of approach but the latest discussion by Mingos in next Monday's Nature Physical Science goes a long way to rationalizing the structural results.

The first order Jahn-Teller effect, which comments on the removal of orbital degeneracy in molecules or ions of high symmetry, has been used widely by inorganic chemists to discuss stereochemical distortions in transition metal complexes. Pearson has recently taken up earlier work by Bader and LonguetHiggins on the second order Jahn-Teller effect, which can make useful predictions of the consequences of "mixing in" electronically excited states on the ground state geometries of molecules. The importance of such admixture in organometallic molecules has been discussed by Mason, and now Mingos shows how simple symmetry considerations of the donor and acceptor orbitals of a Lewis acid-base pair give a clear indication of which nuclear rearrangements are favoured by ligands on coordination. The theory is based on symmetry alone, so it cannot discuss such matters as bond length variations in coordinated olefins and dienes as a function of the metal, the remaining ligands in a molecule and ligand substituents. But the general approach, linked with earlier theories, may prove as useful for organometallic molecules as Walsh's rules have been for simpler systems. 